\title{
CONTRIBUIÇÕES DA AVALIAÇÃO MEDIADA PARA A ESCOLARIZACÃO DE ALUNOS COM DEFICIÊNCIA INTELECTUAL ${ }^{(*)}$
}

\author{
Mariana Corrêa Pitanga de Oliveira \\ Márcia Denise Pletsch \\ Anna Augusta Sampaio de Oliveira ${ }^{(* *)}$
}

\section{INTRODUÇÃO}

\begin{abstract}
A avaliação nos parece ser a questão nuclear da escola, pois é a partir do conhecimento das condições concretas do estudante que podemos exercer uma atuação pedagógica intencional, interventiva e propiciadora do seu desenvolvimento integral, que lhe possibilite sair de um estágio primário para o acesso a funções superiores da ação humana: o uso da linguagem, o exercício da vontade, do poder criativo, da atuação com os signos sociais (OLIVEIRA, 2015b, p. 65).
\end{abstract}

Ao analisarmos os processos avaliativos dirigidos para alunos com deficiência intelectual nos deparamos com concepções avaliativas que se distanciam de práticas que promovam a aprendizagem, uma vez que estas estão centradas apenas nos resultados e não no aprender, no produto e não no processo. Assim, a escola segue promovendo a ideia de avaliar apenas para classificar os alunos (os que aprendem e os que não aprendem), operando com a verificação e não com a avaliação da aprendizagem (LUCKESI, 2011; VALENTIM; OLIVEIRA, 2013; OLIVEIRA 2012, 2015a, 2015b, 2015c; OLIVEIRA; PLETSCH, 2015). Essa é uma visão comum, porém distorcida do que acreditamos ser a função dessa prática pedagógica. Em nossa concepção, a

\footnotetext{
${ }^{(*}$ Este artigo toma como base a dissertação de mestrado da primeira autora, desenvolvida a partir do banco de dados e discussões teóricas de dois projetos em rede: "Escolarização de alunos com deficiência intelectual: políticas públicas, processos cognitivos e avaliação da aprendizagem", realizado com a participação de pesquisadores da UFRRJ, Udesc e Univali, com apoio financeiro do Obeduc/Capes, Faperj e CNPq e "Alfabetização na área da Deficiência Intelectual (PADI)", que envolveu pesquisadores da Unesp, UERJ e UFRRJ, com financiamento do CNPq.

${ }^{(* *)}$ Mariana C. Pitanga de Oliveira. Mestre e Doutoranda do Programa de Pós-graduação em Educação, Contextos Contemporâneos e Demandas Populares (PPGEduc) da Universidade Federal Rural do Rio de Janeiro (UFRRJ). Brasil. E-mail: pitanga.mariana@yahoo.com.br.

Márcia Denise Pletsch. Doutora em Educação. Professora adjunta do Departamento Educação e Sociedade e do Programa de Pós-Graduação em Educação, Contextos Contemporâneos e Demandas Populares (PPGEduc) da Universidade Federal Rural do Rio de Janeiro (UFRRJ). Jovem Cientista da Faperj e pesquisadora do CNPq. E-mail: marciadenisepletsch@gmail.com.
}

Anna Augusta S. Oliveira. Doutora em Educação. Livre-docente em Educação Especial. Professora Adjunta do Departamento de Educação Especial e do Programa de Pós-graduação em Educação da Faculdade de Filosofia e Ciências - Campus de Marília (Unesp). Pesquisadora do CNPq. E-mail: anna.augusta@ marilia.unesp.br. 
avaliação precisa se submeter a uma mudança de paradigma para que possa se transformar em um instrumento que saliente práticas educativas inclusivas.

Em outras palavras, acreditamos que a avaliação deve servir para apontar caminhos e explorar as possibilidades de aprendizagem dos alunos, com ou sem deficiência, de maneira que possibilite ao professor conhecer as estratégias de aquisição do conhecimento e o desenvolvimento atual do sujeito, subsidiando assim reflexões sobre as suas estratégias pedagógicas e a relação entre ensino e aprendizagem (OLIVEIRA et al., 2013). Ao tornar a prática mais significativa podemos também revelar o "vir a ser" do desenvolvimento.

A partir dessas observações, pensando no processo de escolarização de alunos com deficiência intelectual, constatamos que a prática avaliativa deve revelar novas possibilidades e suscitar o desenvolvimento das possibilidades dos alunos, pois concordamos com Valentim (2011) ao afirmar que a função da avaliação é "colaborar no desvelamento do potencial dos alunos com deficiência intelectual, para que ocorra uma sistematização de práticas favorecedoras de aprendizagem” (p. 33). Vale a pena destacar que é preciso levar em consideração as singularidades dos alunos e seus diferentes modos de apreender o conhecimento.

Nesse sentido, a concepção avaliativa que se aproxima da dinâmica inclusiva que temos defendido é a avaliação mediada. Trata-se então, de compreender a avaliação como um processo intencional, capaz de demonstrar como o sujeito aprende e não só o que ele já aprendeu; o que ele pode fazer sozinho e o que ele pode fazer por meio da intervenção do outro (MACHADO, 2013; PLETSCH; OLIVEIRA, 2014; OLIVEIRA, 2015). Esse processo auxilia o professor de maneira a orientá-lo em suas decisões no decorrer da prática pedagógica. Nessa perspectiva,

\footnotetext{
[...] a avaliação deve ser capaz de informar o desenvolvimento atual da criança, a forma como ela enfrenta determinadas situações de aprendizagem, os recursos e o processo que faz uso em determinada atividade. Conhecer o que ela é capaz de fazer, mesmo que com a mediação de outros, permite a elaboração de estratégias de ensino próprias e adequadas a cada aluno em particular. (OLIVEIRA, 2015b, p.78).
}

Portanto, a avaliação mediada pode indicar como o aluno com deficiência intelectual se apropria dos conceitos, ao passo que contribui para o desenvolvimento de suas possibilidades. Desse modo, o ato de avaliar se constitui como um instrumento mediador da aprendizagem.

À luz da abordagem histórico-cultural de Vygotsky, compreendemos as funções psicológicas superiores como processos especificamente humanos que se constituem nas interações sociais. Nessas relações utilizamos significados, estes vão sendo internalizados/apropriados pelo 
sujeito. Cabe dizer que o autor afirma que cultura, em síntese, é o produto da atividade social dos homens (VYGOTSKY, 2012a). Sobre a gênese das funções psicológicas superiores, Vygotsky (2012a) teoriza que a partir de processos psicológicos elementares, de origem biológica (estruturas orgânicas), como os reflexos e as associações simples, se desenvolvem as funções psicológicas superiores (origem cultural), como o controle consciente do comportamento, atenção e lembrança voluntária, memória lógica, pensamento abstrato, formação de conceitos, dentre outros. Tais estruturas se desenvolvem por meio da constante internalização/apropriação de instrumentos e signos no decorrer da vida do sujeito. Nas palavras do autor, ${ }^{1}$

[...] o desenvolvimento cultural se baseia no emprego dos signos e que a sua inclusão no sistema geral do comportamento decorreu inicialmente da forma social, externa. Cabe dizer, em geral, que as relações entre as funções psicológicas superiores foram em tempos relações reais entre os homens. (VYGOTSKY, 2012b, p.147).

Logo, as funções superiores foram antes externas e sociais para depois tornarem-se psicológicas e internalizadas. Para Kassar (2013a) devemos analisar as implicações dessa concepção em alunos com deficiência, pois com exceção dos movimentos incontrolados todos os outros foram construídos na relação com o outro, uma vez que como vimos "o comportamento psíquico humano na sua gênese está imerso na sociedade humana" (p. 159). Dessa maneira, a escolarização de alunos com deficiência intelectual deve privilegiar a construção das funções psicológicas superiores, ao invés de focar só nas elementares. Para ilustrar essa dinâmica, temos como objetivo, neste artigo, analisar as contribuições da avaliação mediada para o desenvolvimento das funções psicológicas superiores, apresentando os dados de nossa pesquisa com um aluno com deficiência intelectual - Carlos. ${ }^{2}$

Em termos metodológicos optamos pela utilização do método instrumental de Vygotsky (2004), ou dinâmico-causal, que conforme afirmação do próprio autor " é um método históricogenérico que proporciona à investigação do comportamento um ponto de vista histórico" (p.98), ou seja, possibilita o estudo das formas superiores de conduta como "um processo, e a estudá-las em movimento [...] e revelar ou colocar em evidência as relações e os nexos dinâmicos-causais que

\footnotetext{
1 [...] el desarrollo cultural se basa en el empleo de los signos y que su inclusión en el sistema general del comportamiento transcurrió inicialmente de forma social, externa. Cabe decir, en general, que las relaciones entre las funciones psíquicas superiores fueron en tiempos relaciones reales entre los hombres (VIGOTSKI, 2012b, p.147).

${ }^{2}$ Seguindo os princípios éticos adotados nessa pesquisa, usaremos nomes fictícios para preservar a identidade dos sujeitos.
} 
constituem a base de todo o fenômeno" (VYGOTSKY, 2012a, p. 101). ${ }^{3}$ O desafio foi, justamente, o estudo do processo de aprendizagem, por meio da avaliação mediada, portanto, em movimento e utilizando a estrutura metodológica construída por Vygotsky ao longo de sua trajetória e que autores como Delari Júnior (2015) apontam ser o método da Psicologia Histórico-Cultural, que pode ser sintetizado como a 1) definição do objeto de análise; 2) os princípios explicativos; 3) a unidade de análise e; 4) a abstração teórico-prática, que nos permite construir hipóteses sobre o fenômeno em observação ou em estudo.

Consideramos importante esclarecer que o método instrumental possibilita o uso de qualquer procedimento de investigação, seja o experimento, a entrevista, a observação entre outros, uma vez que para o autor o método é composto pelo campo teórico e o investigativo e ambos teoria e prática- são indissociáveis e são os instrumentos de pesquisa que nos permitem a aproximação com o objeto de análise.

Dessa forma, como procedimentos de coleta de dados, utilizamos a observação participante com registros em diário de campo e a aplicação de atividades de avaliação da aprendizagem elaboradas por Oliveira (2015), bem como realizamos uma entrevista semiestruturada com a professora do aluno. As observações ocorreram no segundo semestre de 2014, no turno da manhã, uma vez por semana. O sujeito observado foi indicado pela direção da escola, por tratar-se de um aluno que recebeu o diagnóstico de deficiência intelectual. Vejamos como se deu o desenvolvimento desse processo e a participação de Carlos nas avaliações mediadas.

\section{MEMÓRIA, IMAGINAÇÃO E LINGUAGEM: A PARTICIPAÇÃO DE CARLOS NAS AVALIAÇÕES MEDIADAS}

A trajetória escolar de Carlos, aluno com deficiência intelectual, com 10 anos de idade, matriculado no terceiro ano de uma escola comum pertencente ao município do Rio de Janeiro, foi marcada por desafios. A começar pela distância entre seu local de moradia (Nova Iguaçu) e a escola, o que faz com que chegue cansado e sonolento. No entanto, o dado mais intrigante desse processo é que a família descobriu a deficiência recentemente ${ }^{4}$, após indicação da direção da escola por considerar que o aluno tinha muitas dificuldades de aprendizagem. Nas outras instituições que o

\footnotetext{
${ }^{3}$ [...]um processo, y a estudiarlo em movimento [...] revelar o poner de manifiesto las relaciones y nexos dinâmicocausales que constituem la base de todo fenômeno (VYGOTSKY, 2012a p. 101)

${ }^{4}$ A pesquisa foi realizada no segundo semestre de 2014 e aquele era o primeiro ano que o aluno estava frequentando a sala de recursos da escola, pois a descoberta da deficiência se deu no ano anterior.
} 
aluno estudou apenas afirmavam que ele ainda não sabia ler. $\mathrm{Na}$ época da pesquisa, Carlos possuía acompanhamento médico com neurologistas e fonoaudióloga e frequentava a sala de recursos da escola, o que segundo a diretora contribuiu para melhorar as suas dificuldades na linguagem e comunicação.

Embora alguns autores apontem dúvidas sobre referenciais específicos para avaliação do público alvo da educação especial, como podemos observar pela afirmação de Symanski, Pellizzetti e Iacono (2009, p. 110) em relação à deficiência intelectual, "a avaliação desses alunos deveria estar submetida aos mesmos critérios dos demais?”, a definição de critérios e a elaboração de indicadores podem se caracterizar como elementos facilitadores para a prática docente, especialmente no momento em que se apresenta o processo inclusivo brasileiro.

Entendemos que qualquer situação a ser avaliada necessita de referentes. Heredero (2008) em publicação espanhola sobre a análise do processo inclusivo e a qualidade dos espaços escolares, discute os critérios que subsidiam essa avaliação, assim como Souza e Fiscarelli (2009) apontam a busca de novos instrumentos de avaliação de desempenho acadêmico. Claro que é importante considerar, como nos aponta Depresbiteris (2007) que "nenhum instrumento de avaliação é completo em si mesmo" e que a "diversidade de instrumentos permite ao professor a obtenção de um número maior e mais variado de informações" (p.99). Assim, a elaboração e disponibilização de indicadores poderão colaborar com o professor em sua análise do processo de avaliação do aluno com deficiência intelectual. Foi com base nessa perspectiva que buscamos trabalhar com alguns referentes de avaliação.

As atividades foram realizadas semanalmente em duas fases. Assim, Carlos foi avaliado no início e no final do estudo, por meio de instrumentos que permitiram analisar suas condições relacionadas ao desenvolvimento cognitivo, como percepção, atenção, linguagem, simbolismos, representação gráfica etc. Com base nos componentes de avaliação pedagógica, foi construída uma planilha para registros dos dados ${ }^{5}$, a qual foi sendo preenchida a cada etapa de trabalho e nos permitiu uma análise de antes e depois da intervenção.

Imagem 1. Registro de avaliação inicial (PADI)

\footnotetext{
${ }^{5}$ Essa planilha foi elaborada pela equipe de pesquisa envolvida com o Projeto de Alfabetização na área da Deficiência Intelectual e foi utilizada pelos grupos de pesquisa do Rio de Janeiro, São Paulo e Marília (SP) (OLIVEIRA, 2015b).
} 


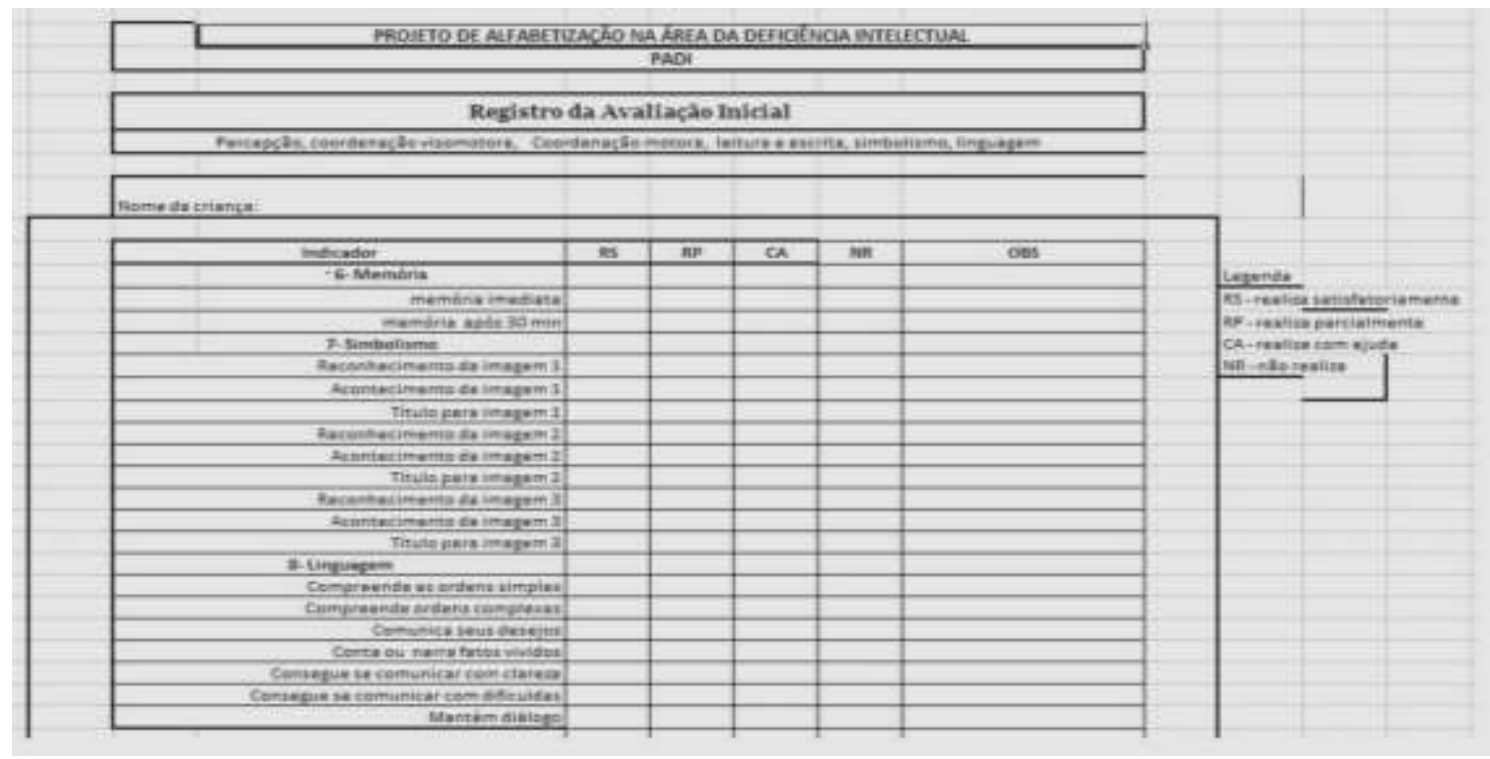

Fonte: Oliveira (2015b)

Na primeira fase do estudo foram elaboradas atividades de avaliação inicial para o uso no desenvolvimento do PADI, bem como leitura e sondagem de escrita com palavras e frase do mesmo grupo semântico. Para análise do desempenho dos alunos utilizamos a indicação dos níveis de aprendizagem, com o objetivo, inclusive, de assinalar o que estava na zona de iminência ou na zona real do desenvolvimento (VIGOSTKI, 2000). Assim, foram usadas as seguintes indicações ao avaliar Carlos: RS - realiza satisfatoriamente; RP - realiza parcialmente; CA - realiza com ajuda; NA - não apresentado ao aluno e NR - não realiza. Essas indicações foram utilizadas com base em referencial de avaliação anteriormente elaborado para avaliar alunos com deficiência intelectual em classes comuns do ensino regular (SÃO PAULO, 2008; 2012). Posteriormente, os valores qualitativos foram transformados em valores numéricos com o único objetivo de construir os gráficos que possibilitassem a análise da evolução de Carlos, assim, usamos os seguintes valores: RS - realiza satisfatoriamente (3); RP - realiza parcialmente (2); CA - realiza com ajuda (1); NR não realiza (0.5) e NA - não apresentado ao aluno (0). Essa avaliação inicial foi realizada em duas etapas com períodos de descanso para que Carlos não se cansasse e o cansaço não fosse fator prejudicial à avaliação.

Na segunda fase realizamos a aplicação de um Plano de Intervenção Semanal (PIS). A intervenção teve foco pedagógico e se caracterizou, por propostas dinâmicas em relação à leitura e escrita partindo de temas geradores com base em canções, histórias, lendas e parlendas conhecidas por Carlos. Nessa proposta, foram realizadas atividades que possuíam o objetivo de desafiá-lo intelectualmente e apoiá-lo em relação à aquisição/apropriação da leitura e da escrita, exercendo o papel mediador do outro e dos signos e mantendo a proposta de uma avaliação mediada e contínua. 
Dessa maneira, as atividades de avaliação da aprendizagem e as intervenções realizadas constituíram-se como propostas de avaliação mediada, e é a partir desse olhar que iremos descrevêlas.

É pertinente ressaltar que durante a entrevista semiestruturada com a professora de Carlos nos foi sinalizada a dificuldade do aluno em se concentrar na atividade, bem como de se expressar e de organizar o pensamento para produzir um texto, por exemplo, pois ele ainda não havia desenvolvido muito bem a linguagem. A memória do aluno, segundo Patrícia - sua professora -, era flutuante e dependente do contexto. Em suas palavras: "Ele se dispersa facilmente, falta organização interna para o Carlos, a externa já foi trabalhada" (Fala da professora - registro em diário de campo durante a entrevista). Por esses e outros aspectos destacamos para análise atividades, com ou sem mediação, que envolviam as seguintes categorias: memória, imaginação e linguagem.

Para dar início as nossas reflexões sobre a participação do aluno nas provas, apresentamos a “prova de memória' los em dois mome Observem nas image

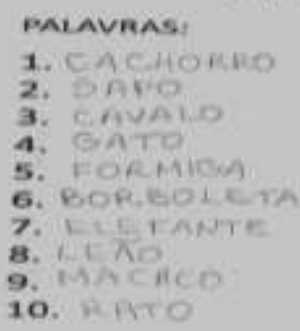

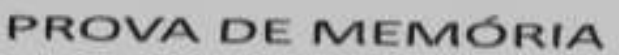
de animais e repeti(após 30 minutos).

Fonte: Oliveira (2015b)

$\mathrm{Na}$ imagem 2 temos a proposta de palavras a serem ditas para Carlos. O pesquisador deveria anotar sua memória imediata e, posteriormente, após 30 minutos da realização da atividade.

Imagem 3. Registro da prova de memória

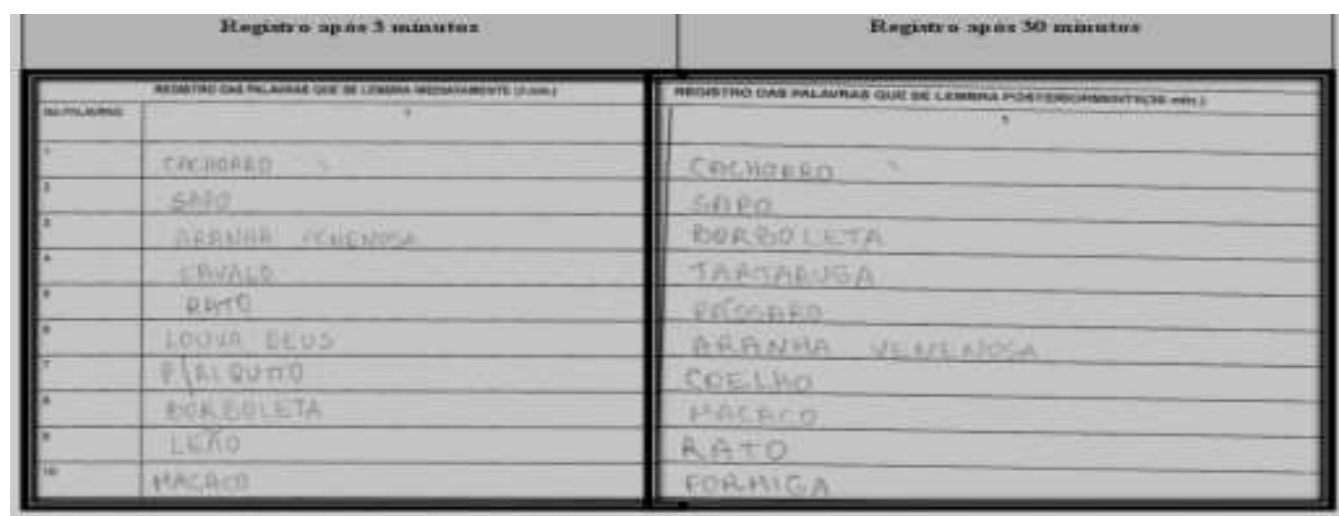

Fonte: Oliveira (2015b) 
Nos registros ${ }^{6}$ apresentados podemos notar que inicialmente Carlos memorizou sete nomes corretos e no segundo seis nomes corretos, apesar de já ter passado trinta minutos do início da prova (durante o tempo de intervalo ele continuou fazendo outras atividades). Além do bom desempenho do aluno, nessa atividade o que mais nos chamou atenção é que ele sabia que deveria responder dez nomes de animais e quando não se lembrava de algum nome ele utilizava a imaginação para responder. Respostas como aranha venenosa que não foram apresentadas pela pesquisadora ao aluno (ver imagem 2) estavam em ambos os registros, demonstrando não só a imagem das experiências anteriores, mas também a reelaboração dessa imagem. Assim, nesse episódio o aluno evidencia o que Vygotsky dizia sobre a intrínseca relação entre memória e imaginação (VYGOTSKY, 2009).

De acordo com essa visão, Smolka (2009) explica que para Vygotsky a imaginação é compreendida "[...] como atividade humana (não uma faculdade dada a priori), elaborada com base na experiência sensível transformada pela própria produção do homem, pela possibilidade de significação, pela cultura" (p.20). Para Facci e Brandão (2008), a imaginação contribui para que o "material" advindo da experiência social seja associado com novas imagens e registrados, isso eleva o processo de memorização e desenvolve os processos psicológicos superiores, por meio da mediação.

Embasados por esses argumentos, acreditamos que a relação entre memória e imaginação nos leva a compreender que temos que ampliar a experiência do sujeito para solidificar sua atividade criadora, visto que a última está apoiada na apropriação das experiências sociais. Tal premissa é defendida por Vygotsky (2009). Para isso, no fazer pedagógico é preciso analisar e conhecer as experiências e condições de vida dos alunos, pois o professor tem um papel essencial como orientador/mediador. Dessa maneira, por mais que a atividade destacada tenha sido realizada sem a intervenção direta do pesquisador, ao incentivar o aluno a responder e aceitar como resposta na prova o fruto de sua imaginação, orienta o pensamento do aluno para o despertar de novas criações. Para ilustrar como esse processo se revela no desenho destacamos a atividade a seguir:

\footnotetext{
${ }^{6} \mathrm{O}$ registro da atividade foi feito pela pesquisadora, o aluno respondia oralmente e não precisava responder na mesma ordem que os animais apareciam na imagem 2.
} 
Imagem 4. Desenho livre.

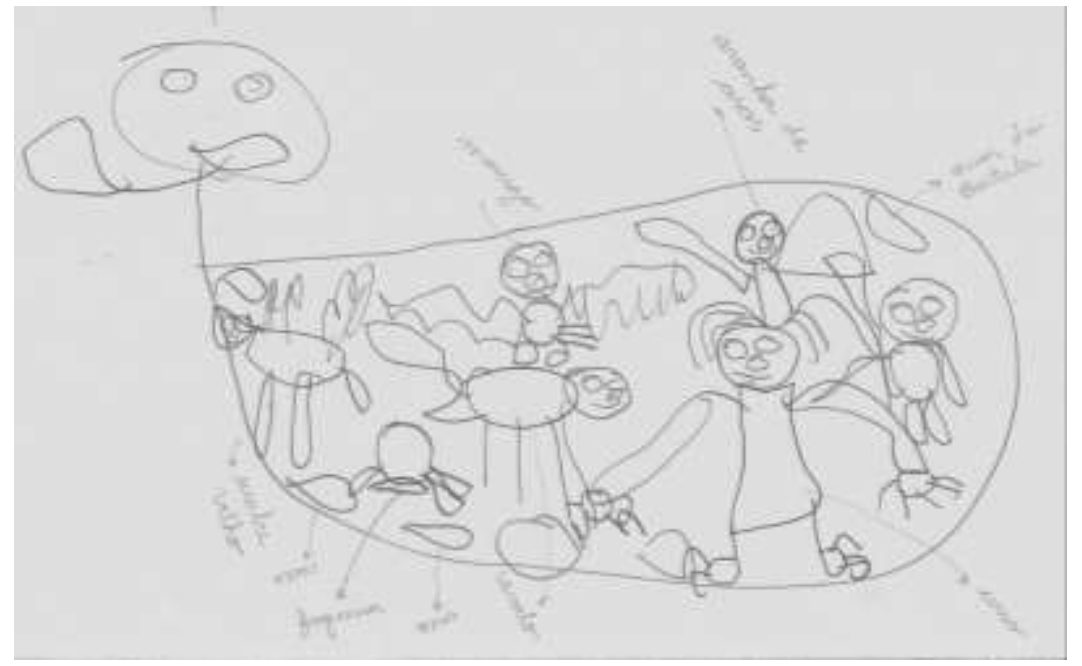

Fonte: Oliveira (2015b)

No desenho observamos que o aluno optou por uma figura lendária do folclore brasileiro - o boitatá. $\mathrm{Na}$ imagem Carlos utiliza elementos fantasiosos como percepções da realidade. Ao ser questionado sobre a presença de outros animais "dentro do boitatá" ele responde que o animal comeu: um morcego, uma aranha de asas, um urso, um cavalo e um urubu velho que estavam na floresta. Até então ainda não tínhamos entendido a riqueza de sua criação. Após essa primeira fala, questionamos o aluno sobre outras duas representações que estavam no interior do "animal" e prontamente ele respondeu: "São os ossos do boitatá e a fogueira é claro". Ao pesquisar sobre a lenda do boitatá verificamos que o animal é uma "cobra de fogo" que vem para assustar as pessoas que colocam fogo nas matas das florestas (LAZZAROTTI, 2004). Podemos dizer então, que é por isso que no desenho de Carlos o boitatá engoliu uma fogueira e animais que estavam na floresta. Com base em Vygotsky (2009) podemos inferir que esse processo representa uma das formas de relação entre imaginação e realidade, pois para o autor "[...] esses produtos da imaginação consistem de elementos da realidade modificados e reelaborados" (p.24). Na criação do aluno temos, por um lado, uma lenda - um animal irreal, por outro, diferentes elementos reais (os animais, a fogueira, os ossos do animal) que foram reelaborados, mas que já estavam presentes em sua memória.

Ao analisar o sentido do desenho, Vygotsky (2009) revela que “[...] a criança desenha de memória. Ela desenha o que sabe sobre a coisa" (p.107). Isso contribui para que enquanto o aluno está desenhando ele pense sobre o objeto significando-o. No decorrer desse desenvolvimento, concordamos com Smolka (2009) que “[...] a percepção da criança vai se tornando verbalizada e se transforma simultaneamente à elaboração de formas voluntárias de atenção e de memória” (p.113). Com tal característica, a imaginação para Vygotsky (2009) ao ser realizada em uma palavra, ou em 
uma obra, passa a fazer parte do sistema de funções psicológicas superiores, articulando-se à atividade voluntária e à elaboração da consciência. Por isso devemos "cultivar" (termo do autor) a imaginação criadora na idade escolar.

Nessa dinâmica, constatamos que a atividade por meio da intervenção pedagógica estimulou o aluno a narrar a construção do desenho, bem como expressar o significado que a imagem possui para ele. Frente a estes aspectos, nos aproximamos do estudo de Cruz (2011) sobre a abordagem de Vygotsky para afirmar que:

O significado é móvel, aberto, incompleto e sua significação se constitui, se transforma e só pode ser explicada pela/na interlocução. A questão da significação implica a atividade dos homens com e na linguagem que, enquanto produto histórico e atividade humana, é também produção e criação (p. 98).

A este respeito, observamos que o desenvolvimento da imaginação está ligado ao desenvolvimento da linguagem. Visando demonstrar o desenvolvimento da linguagem do aluno e as contribuições da mediação pedagógica no processo avaliativo (avaliação mediada), apresentamos a seguir alguns episódios da participação de Carlos na segunda fase das provas - as intervenções.

Durante a fase de intervenção, as atividades foram elaboradas a partir de um personagem que acabava sendo a temática de todas as outras atividades. Por exemplo, no trava-língua do rato, primeira atividade que realizamos com o aluno, todas as demais foram trabalhadas nesse dia relacionavam-se com o personagem rato. Nesse bloco de atividades trabalhamos o desenvolvimento da linguagem oral, a partir da leitura e interpretação da história. Nas avaliações o aluno precisava interagir e comunicar-se para responder as atividades propostas pela interventora, além de organizar suas ações, planejar e expressar seus desejos. Dentre os objetivos, destacamos: desenvolver a linguagem, atenção, concentração e memória lógica. ${ }^{7}$

Para verificar se de fato o aluno tinha se apropriado e compreendido a história e desenvolver a memória e sequência lógica, propomos que ele recontasse a história do rato que mencionamos anteriormente, dessa vez utilizando como recurso fantoche confeccionados por ele, das imagens (o rato sozinho, o rato roendo a camisa do rei, a camisa vermelha do rei e a imagem do rei) com os personagens colados em palitos de churrasco. Carlos organizou a sequência da história da seguinte maneira: $1^{\circ}$ a imagem do rato, $2^{\circ}$ a camisa, $3^{\circ}$ o rato roendo a camisa e $4^{\circ}$ a imagem do rei. A nosso ver a sequência lógica estava correta, pois ele não poderia apresentar a imagem do rato roendo a camisa antes de expor a camisa propriamente dita. A atitude do aluno nos surpreendeu, pois quando

\footnotetext{
${ }^{7}$ Uma análise completa sobre as avaliações mediadas com Carlos pode ser vista em Oliveira (2016).
} 
apresentamos o trava-língua não tínhamos observado este fato. Resolvemos verificar se essa ação do aluno também seria representada ao contar a história com os fantoches. O relato a seguir mostra a analogia: "O rato saiu de sua casa, viu a roupa e começou a roer a roupa do rei e o rei Ricardo ficou furioso" (registro em diário de campo em setembro de 2014).

Como vimos, o recurso utilizado contribuiu para que o aluno ampliasse o seu vocabulário, além de desenvolver a capacidade de contar fatos em sequência lógica. Ele não só se lembrou da história como apresentou suas impressões sobre o comportamento dos personagens a partir da sua imaginação. Sobre as aproximações entre imaginação e linguagem, Cruz (2011) revela que existe

[...] uma certa duplicidade no tratamento dado por Vygotsky à imaginação que, num momento, é entendida como atividade que reelabora, em uma nova imagem, impressões da realidade imediata, numa espécie de generalização que, como tal, acaba submetida aos poderes do pensamento conceitual abstrato. Em outro, a imaginação aparece como distanciamento da realidade, como produção de imagens que não existem na realidade, ou seja, como criação, possibilitada graças ao poder da linguagem que nos liberta do imediato, do aqui e agora dos sentidos e das percepções (p. 97-98).

Assim, para Vygotsky (2007) agir independentemente da situação perceptual imediata e criar uma situação imaginária pode ser considerada uma forma de desenvolver o pensamento abstrato. Cabe lembrar que inicialmente Carlos apresentou dificuldades para organizar o pensamento e a necessidade de desenvolvimento da linguagem, essas foram queixas inclusive de sua professora. No decorrer das atividades ou provas mediadas presenciamos mudanças nessas concepções. Mais uma vez notamos aproximações entre essas práticas avaliativas e a perspectiva histórico-cultural, visto que em uma de suas teses Vygotsky (2012b) aponta que a criança que tem seu desenvolvimento comprometido por algum deficiência, não é uma criança menos desenvolvida que crianças normais, “[...] mas as crianças com deficiência se desenvolvem de modo distinto, por um caminho distinto, com outros meios, e para o professor é importante conhecer as particularidades do caminho pelo qual deve conduzir a criança" ${ }^{8}$ (p.17). Na busca por esses caminhos de aprendizagem para Carlos, seguimos com a aplicação de atividades que por meio da interação entre pesquisadora e aluno propiciaram o desenvolvimento das funções psicológicas superiores.

Nas semanas seguintes, todas as atividades pedagógicas foram elaboradas no contexto de brincadeiras cantadas e músicas, como a cantiga popular da "Dona Baratinha" "A barata diz que

\footnotetext{
8 “[...] pero los niños com defecto lo logran de distinto modo, por un camino distinto, con otros medios, y para el pedagogo es importante conocer la peculiaridad del camino por el cual debe conducir al niño" (p.17).
} 
tem" e "Seu lobato tinha um sítio", por exemplo. Em síntese, as demais atividades aplicadas continham vários materiais de sondagem de escrita, leitura, construção de palavras, coordenação motora, etc. Atividades que buscavam alcançar os caminhos percorridos pela imaginação, memória e linguagem de Carlos, como jogo da memória com ilustrações e palavras das histórias, fantoche para colorir, recortar e montar, dominó de palavras com figuras, diagrama e sondagem de escrita de palavras pertencentes à música como eixo temático.

Com as devidas mediações pedagógicas, as atividades nos permitiram compreender a forma como Carlos elaborava o seu pensamento. Valorizar a sua imaginação criadora e a partir desta pensar em atividades que visassem alcançar formas abstratas de construção do pensamento e linguagem do aluno, só foram possíveis a partir do diálogo e da intervenção sistematizada durante a aplicação das provas. Dessa maneira, ressaltamos a importância de compreender as práticas pedagógicas como práticas mediadas e dialógicas. Conforme salienta Tacca (2014):

Entendemos, assim, que a estratégia pedagógica necessária aos processos de ensinoaprendizagem tem seus alicerces nas relações com a utilização plena do diálogo no trabalho compartilhado. O diálogo é o cerne da relação na aprendizagem, em que as partes envolvidas fazem trocas e negociam os diferentes significados do objeto do conhecimento, o que dá relevância ao papel ativo e altamente reflexivo, emocional e criativo do aluno e do professor. O conhecimento, assim, distancia-se de uma perspectiva mecanicista ou cognitivista que enfatiza quase que, exclusivamente, o produto da aprendizagem, ficando entendido como uma dinâmica que se constrói na confluência dialética entre o individual e o social, tendo em vista o desenvolvimento integral dos sujeitos envolvidos na educação (p. 50).

Partilhamos dessa opinião. Essas interações dialógicas estabelecidas entre professor e aluno e/ou aluno e aluno durante as práticas pedagógicas aumentam as possibilidades de apreensão dos conteúdos curriculares para alunos com deficiência intelectual - especialmente de conhecimentos que envolvem operações simbólicas. Partindo desse ponto de vista, os dados nos permitem observar que a avaliação mediada com suas atividades colaborativas aproxima-nos de outro conceito do estatuto teórico de Vygotsky que perpassa todo o processo de desenvolvimento humano: a zona de desenvolvimento proximal (ZDP). ${ }^{10}$ Em nosso entendimento a ZDP dialoga com as práticas pedagógicas que utilizam a mediação como base, visto que sugere que a criança com deficiência intelectual pode atingir níveis mais elevados de desenvolvimento quando soluciona seus problemas

\footnotetext{
${ }^{9}$ Atividades disponíveis no site do Grupo de Estudo e Pesquisa em Inclusão - GEPIS (www.gepis.com.br)

10 Reconhecemos a importância da terminologia zona de desenvolvimento iminente utilizada por Prestes (2010), concordando com a autora que a característica essencial do termo são as possibilidades de desenvolvimento, porém optamos nesse trabalho por utilizar a terminologia utilizada nas traduções das obras aqui apresentadas.
} 
com o auxílio do outro em uma proposta colaborativa, implicando assim "a transformação de um processo interpessoal (social) num processo intrapessoal e a internalização dos conhecimentos" (PLETSCH; OLIVEIRA, 2013, p. 72). A ZDP está entre o que já aconteceu (real) e o que está em iminência e poderá ocorrer (potencial) e é nesse entremeio imensurável que a intervenção pedagógica deve ocorrer.

Em uma analogia mencionada durante uma de suas aulas, Pletsch (2013) afirma que a ZDP pode ser representada pela alvorada, isto é, pelo caminho até o amanhecer (quando ainda não é dia, mas também não é noite). Esse caminho que o sujeito tem que prosseguir precisa ser mediado, por mais que a gente não possa ter precisão do que irá ocorrer nesse percurso e é essa trajetória que deve ser avaliada. Ao invés de focarmos em um único ponto de referência, devemos concentrar nossas intervenções no despontar de um novo amanhecer.

Igualmente, a zona de desenvolvimento proximal, conforme aponta Costas (2003), “[...] pode ser interpretada prospectivamente no que se refere às funções superiores que estão se construindo por meio das inter-relações com outras pessoas, com signos e com ferramentas" (p. 77). A potencialidade dessas ações está permeada por funções já amadurecidas e outras que ainda não amadureceram, em um movimento dialético, então se hoje a criança não desempenha ainda uma determinada atividade sozinha, amanhã após a internalização/apropriação do conceito e a compreensão de tal tarefa ela poderá desempenhar a mesma sem ajuda (VYGOTSKY, 2007). Logo, com o auxílio da mediação/intervenção pedagógica significativa impulsionando a ZDP, o que era potencial pode vir a se tornar real.

À vista disso, é no desenvolvimento que está em iminência que o professor deve atuar. De acordo com Kassar (2013b), esse conceito traz aspectos fundamentais que devem ser considerados, são eles:

[...] $1^{\circ}$ Existem sempre possibilidades e habilidades que estão em processo de amadurecimento; $2^{\circ} \mathrm{O}$ aprendizado cria a Zona de Desenvolvimento Proximal, pois desperta/impulsiona vários processos internos de desenvolvimento que só são viáveis a partir do contato do indivíduo com o meio cultural. Essa abordagem traz implicações para a prática pedagógica do educador, pois destaca que o aprendizado escolar bem elaborado produz mudanças inteiramente novas e substanciais no desenvolvimento infantil (p.104).

É nessa direção que enfatizamos a importância da escola em difundir o ato avaliativo mediado e intencional, por meio de estratégias pedagógicas orientadas para a produção de atividades que façam sentido para o sujeito e não só para verificar se ele aprendeu o conteúdo, 
rompendo assim com o paradigma tradicional de ensino (OLIVEIRA; PLETSCH, 2015). Essa ideia é reforçada por Tacca (2014):

Nesse caso, ao receber uma resposta do aluno, o professor vai dialogar com ele a fim de compreender o processo de significação percorrido e alcançar, se for o caso, os momentos que ocorreram equívocos, o que lhes esclarecerá sobre os novos apoios para reflexão que deve dar ao aluno, para que ele retome e reelabore sua aprendizagem (p. 48).

$\mathrm{Na}$ linha desses argumentos, nos deparamos com a ideia de que não devemos focalizar nossas ações no déficit biológico do aluno com deficiência, ao invés disso alicerçar a aprendizagem na interação com o outro, nas trocas mediatizadas entre o individual e o social, tendo em vista o desenvolvimento. Esses aspectos nos aproximam do conceito de compensação desenvolvido por Vygotsky (2012b) "A tese central da defectologia atual é a seguinte: todo defeito cria os estímulos para elaborar uma compensação" (p. 14), ${ }^{11}$ que em suma diz que a deficiência de uma função ou lesão de um órgão, faz com que o sistema nervoso central e o aparato psíquico assumam a tarefa de compensar o defeito, apesar dos resultados nem sempre serem vitoriosos.

Ainda sobre esta perspectiva, podemos notar que a partir da compensação o aluno é capaz de se transformar e apropriar-se da cultura mobilizando forças compensatórias, que afirmam a possibilidade de construções mentais para além da deficiência. $\mathrm{O}$ ato de compensar revela o que é o humano. Por conseguinte, Anache (2011) afirma que devemos analisar os artifícios compensatórios do aluno a fim de reconhecer não só os núcleos primários (nível de comprometimento neurológico), como também os secundários (nível de experiências socioculturais vividas) da deficiência, pois estes influenciam diretamente no processo de ensino e aprendizagem do mesmo. Portanto, entendemos que a partir da aplicação de práticas pedagógicas como a avaliação mediada que atuam na ZDP do aluno com deficiência intelectual, criam-se alternativas que podem vir a propiciar o desenvolvimento de áreas potenciais e compensatórias.

\section{CONSIDERAÇÕES FINAIS}

A partir das reflexões apresentadas ao longo deste artigo concluímos que a avaliação mediada, por meio de sua intrínseca mediação pedagógica, torna-se um instrumento capaz de atuar na zona de desenvolvimento proximal do aluno com deficiência intelectual e assim contribuir com o

\footnotetext{
11، "La tesis central de la defectología actual es la siguiente: todo defecto crea los estímulos para elaborar una compensación” (VYGOTSKY, 2012b, p. 14).
} 
desenvolvimento de suas funções psicológicas superiores, ao passo que promove mecanismos de apropriação conceitual e compensa o "defeito".

No processo de coleta de dados, também ficou evidente que ao elaborarmos uma avaliação que contemple as especificidades do desenvolvimento de alunos com deficiência intelectual esta passa a ser também um instrumento mediador do ensino e da aprendizagem. Isto é, à medida que a intervenção mediada do professor revela caminhos para o aluno se apropriar de um determinado conceito, a própria avaliação também é mediadora desse processo, sinalizando novas possibilidades. Dessa maneira, os dados revelaram a importância da mediação e da interação dialógica com o outro para a promoção das possibilidades de aprendizagem e do desenvolvimento humano. As provas avaliativas demonstraram relações significativas da aprendizagem permeada pelo processo de elaboração conceitual nos cotidianos escolares. A este respeito, é pertinente mencionar que na participação do aluno nas provas encontramos indícios de efetivas possibilidades de apropriação conceitual e desenvolvimento. Sendo assim, conforme revela a epígrafe desse trabalho, promover práticas avaliativas que contemplem as especificidades de todos os alunos, reconhecendo as dinâmicas da aprendizagem de cada um é o grande desafio da escola. Os dados também apontam que o professor enquanto mediar é o responsável por planejar atividades que contribuam para que alunos como Carlos possam compensar as suas especificidades, pois o fazer pedagógico em si deve buscar descobrir o modo participar de cada um aprender. Dessa maneira, a avaliação mediada pode suscitar novos caminhos para a escolarização de alunos com deficiência intelectual. 


\section{REFERÊNCIAS}

ANACHE, Alexandra. A aprendizagem de pessoas com deficiência intelectual: desafios para o professor. In: MARTINEZ, Albertina Mitjáns; TACCA, Maria Carmen. (Orgs.). Possibilidades de aprendizagem: ações pedagógicas para alunos com dificuldade e deficiência. Campinas, SP: Alínea, 2011. p. 109-138.

COSTAS, Fabiane A. Tonetto. O processo de formação de conceitos científicos em crianças com necessidades educacionais especiais na primeira série do ensino fundamental. 247f. Tese (Doutorado) - Faculdade de Educação, Universidade Federal do Rio Grande do Sul, 2003.

CRUZ, Maria N. Imaginação, linguagem e elaboração de conhecimento na perspectiva da psicologia histórico-cultural de Vygotsky. In: SMOLKA, Ana Luiza B.; NOGUEIRA, Ana Lúcia H. Emoção, memória, imaginação: a constituição do desenvolvimento humano na história e na cultura. Campinas, SP: Mercado de Letras, 2011. p. 85-104.

DELARI JR. Achiles. Questões de Método em Vygotsky: busca da verdade e caminhos da cognição. In: TULESKI, Silvana C.; CHAVES, Marta.; LEITE, Hilusca Alves. (Orgs.). Materialismo Histórico-dialético com fundamento da Psicologia Histórico-cultural: método e metodologia de pesquisa. Maringá, PR: EDUEM, 2015. 194p.

DEPRESBITERIS, Léa. Instrumentos de avaliação: reflexões sobre seu significado. MELO, Marcos M. (Org.). Avaliação na Educação. Pinhais, PR: Editora Melo, 2007. p. 95-102.

FACCI, Marilda G. Dias; BRANDÃO, Silvia H. A importância da mediação para o desenvolvimento das funções psicológicas superiores de alunos da educação especial: contribuições da psicologia histórico-cultural. Curitiba: Secretaria de Estado da Educação do Paraná, 2008. (Produção didático-pedagógica PDE/UEM).

HEREDERO, Eládio Sebastían. A la calidad de la educación desde los espacios escolares - visión del profesorado y perpestivas en la educación castellano-machega. Universidad de Alcalá, 2008.

KASSAR, Mônica C. Magalhães. Funções mentais superiores e a formação da consciência em sujeitos com deficiência mental grave: implicações pedagógicas. In: SMOLKA, Ana L. Bustamante; NOGUEIRA, Ana L. Horta. (Orgs.). Estudos na perspectiva de Vygotsky: gênese e emergência das funções psicológicas. Campinas, SP: Mercado de Letras. 2013a. p. 151-172.

Neurologia e implicações pedagógicas. In: MELETTI, Silvia M. Ferreira; KASSAR, M.C. Magalhães. (Orgs.). Escolarização de alunos com deficiências: desafios e possibilidades. São Paulo: Mercado de Letras, 2013b. p. 95-108.

LAZZAROTTI, Ronaldo. Boitatá, a cobra que apaga incêndios. Coleção Festa na floresta. Leitura, 2004.

LUCKESI, Cipriano C. Avaliação da aprendizagem escolar: estudos e proposições. 22. ed. São Paulo: Cortez, 2011.

MACHADO, Rosicler Salete. Avaliação do potencial de aprendizagem de alunos com deficiência Intelectual. 2013. 150 f. Dissertação (Mestrado em Educação) - Universidade do Vale do Itajaí, Santa Catarina, 2013.

OLIVEIRA, Anna A.S. A questão da leitura e escrita na área da deficiência intelectual: qual a melhor forma de ensino? Projeto de pesquisa (UNESP), 2012.

et al. Avaliação pedagógica: foco na deficiência intelectual numa perspectiva inclusiva. São Paulo: Cultura Acadêmica; Marília: Oficina Universitária, 2013.

Avaliação da condição de alfabetização de estudantes com Deficiência Intelectual no contexto inclusivo. In: Arquivos Analíticos de Políticas Educativas, 23(31). Dossiê Educação Especial: Diferenças, Currículo e Processos de Ensino e Aprendizagem II. 2015.

A questão da leitura e escrita na área da deficiência intelectual: qual a melhor forma de ensino? Relatório científico (no prelo), 2015b.

- Estudos na área da deficiência intelectual: avaliação pedagógica, aprendizagem e currículo escolar. 2015. 358f. Tese. (Livre-docência em Educação Especial) - Universidade Estadual Paulista "Júlio de Mesquita Filho". UNESP, campus de Marília. 2015c.

OLIVEIRA, Mariana C. Pitanga. A escolarização de alunos com deficiência intelectual à luz da perspectiva históricocultural: avaliação mediada e apropriação conceitual. 133 p. Dissertação (Mestrado em Educação) - PPGEduc / Universidade Federal Rural do Rio de Janeiro. 2016. 
OLIVEIRA, Mariana C.P.; PLETSCH, Márcia D. A avaliação da aprendizagem de alunos com deficiência intelectual em contextos inclusivos. In: PLETSCH, M.D.; SOUZA, F.F. (Orgs.). Observatório de educação especial e inclusão escolar: balanço das pesquisas e das práticas na Baixada Fluminense. São Carlos: Marquezine \& Manzini: ABPEE, 2015.

PLETSCH, Márcia Denise. Notas de Aula. Departamento de Educação e Sociedade do Instituto Multidisciplinar: Disciplina Educação Especial. UFRRJ/IM, 2013.

; OLIVEIRA, Anna A. Sampaio. O Atendimento educacional especializado (AEE): análise da sua relação com o processo de inclusão escolar na área da deficiência intelectual. In: MILANEZ, Simone Ghedini C.; OLIVEIRA, Anna A. Sampaio; MISQUIATTI, Andréia R. Nunes. (Orgs.). Atendimento Educacional Especializado para alunos com deficiência intelectual e transtornos globais do desenvolvimento. São Paulo, Cultura acadêmica - Oficina universitária, 2013. p. 61-82

; OLIVEIRA, Mariana C. Pitanga. Políticas de educação inclusiva: considerações sobre a avaliação da aprendizagem de alunos com deficiência intelectual. Revista Educação, Artes e Inclusão, v. 10, n. 2, p. 125-137, 2014.

PRESTES, Zóia R. Quando não é quase a mesma coisa: análise de traduções de Lev Semionovitch Vygotsky no Brasil - Repercussões no campo educacional. 2010. 295fls. Tese. (Doutorado em Educação) - Programa de Pós-Graduação em Educação, Universidade de Brasília/UnB, 2010.

SÃO PAULO (município). Secretaria Municipal de Educação. Diretoria de Orientação Técnica. Referencial sobre Avaliação da Aprendizagem na área da Deficiência Intelectual. Secretaria Municipal de Educação - São Paulo: SME / DOT, 2008.

(município). Secretaria Municipal de Educação. Diretoria de Orientação Técnica. Referencial sobre Avaliação da Aprendizagem na área da Deficiência Intelectual - Ensino fundamental Ciclo II e Educação de Jovens e Adultos. Secretaria Municipal de Educação - São Paulo: SME / DOT, 2012.

SMOLKA, Ana Luiza Bustamante. Comentários do livro (obra comentada). In: Imaginação e criação na infância. São Paulo: Ática, 2009.

SOUZA, Claudio Gomide; FISCARELLI, Sílvio Henrique. Evaluación de desempeño y reacción: utilización de nuevas tecnologías. In: HEREDERO, Eládio Sebastían; BRIS, Mário Martíns. Formación del ciudadano en un mundo global una mirada desde los contextos español y brasileño. Universidad de Alcalá, 2009.

SZYMANSKI, Maria Lídia Sisca; PELLIZZETTI, I.G.; IACONO, Jane Peruzo. O dilema de avaliar conhecimento na escola: a trajetória de um aluno com déficit intelectual. In: MANZINI, Eduardo José; MARQUEZINE, Maria Cristina; BUSTO, Rosângela Marques; TANAKA, Eliza Dieko Oshiro; FUJISAWA. Dirce Shizuko Procedimentos de Ensino e Avaliação em Educação Especial. Londrina, PR: ABPEE, 2009.

TACCA, Maria Carmem Villela Rosa. Estratégias pedagógicas: conceituação e desdobramentos com o foco nas relações professor-aluno. In: TACCA, Maria Carmem V. Rosa. (Org.). Aprendizagem e trabalho pedagógico. 3. ed. Campinas, São Paulo: Alínea, 2014. p. 45-68.

VALENTIM, Fernanda Oscar Dourado. Inclusão de alunos com deficiência intelectual: considerações sobre avaliação da aprendizagem escolar. 2011. 143 f. Dissertação (Mestrado em Educação) - Universidade Estadual Paulista, Marília, 2011.

; OLIVEIRA, Anna A. Sampaio. Avaliação da aprendizagem e deficiência intelectual na perspectiva de professores do ensino comum. Rev. Diálogo Educ., Curitiba, v. 13, n. 40, p. 851-871, set./dez. 2013.

VYGOTSKY, Lev Semenovich. Teoria e Método em Psicologia. 3. ed. São Paulo: Martins Fontes, 2004. Fontes, 2007.

A formação social da mente. Trad.: J.C. NETO; L.S.M. BARRETO; S.C. AFECHE. 7. ed. São Paulo: Martins . Imaginação e criação na infância. São Paulo: Ática, 2009.

. Obras escogidas III: problemas del desarrollo de la psique (1995). Madrid: Machado, 2012a.

Obras escolhidas V: fundamentos de defectologia (1997). Madrid: Machado, 2012b. 


\title{
RESUMO
}

Este artigo discute, à luz da perspectiva histórico-cultural, as contribuições da avaliação mediada no processo de escolarização de alunos com deficiência intelectual. Para isso, optamos por uma pesquisa qualitativa, do tipo estudo de caso com um aluno do $3^{\circ}$ ano do Ensino Fundamental de uma escola situada no município do Rio de Janeiro (RJ). Como procedimentos de coleta de dados, realizamos a observação participante com registros em diário de campo, entrevista semiestruturada com a professora e aplicamos atividades de avaliação da aprendizagem. Os resultados mostraram, entre outros aspectos, que a avaliação mediada por meio de sua intrínseca mediação pedagógica foi positiva e atuou na zona de desenvolvimento proximal do aluno, contribuindo, assim, para a apropriação de conceitos escolares.

Palavras-chave: Deficiência intelectual. Avaliação mediada. Processos psicológicos superiores.

\section{CONTRIBUTIONS OF MEDIATED EVALUATION FOR THE SCHOOLING OF STUDENTS WITH INTELLECTUAL DISABILITY}

\begin{abstract}
This paper discusses, in the light of the historical-cultural perspective, the contributions of mediated evaluation in the schooling process of students with intellectual disabilities. For this, we chose a qualitative research, case study type with a student from the 3rd grade of an elementary school located in the city of Rio de Janeiro (RJ). As for data collection procedures, we conducted participant observation registered in a field diary, semi-structured interviews with the teacher and we applied learning evaluation activities. The results showed, among other aspects, that the mediated evaluation through its intrinsic pedagogical mediation was positive and acted in the zone of proximal development of the student, thereby contributing to the appropriation of school concepts.
\end{abstract}

Keywords: Intellectual Disability. Mediated evaluation. Higher psychological processes.

Submetido abril 2016

Aprovado jun. 2016 